\title{
Relationship between vegetable and carotene intake and risk of prostate cancer: the JACC study
}

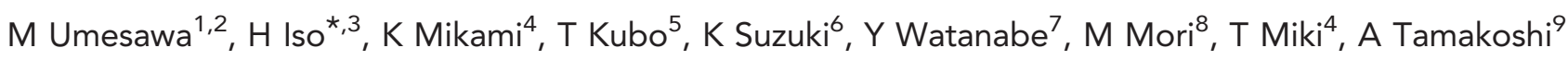 \\ and JACC Study Group
}

${ }^{1}$ Department of Public Health, Dokkyo Medical University School of Medicine, Mibu, Tochigi 321-0293, Japan; ${ }^{2}$ Department of Public Health Medicine, Faculty of Medicine, University of Tsukuba, Tsukuba 305-8577, Japan; ${ }^{3}$ Public Health, Department of Social and Environmental Medicine, Graduate School of Medicine, Osaka University, Osaka 565-0871, Japan; ${ }^{4}$ Department of Urology, Kyoto Prefectural University of Medicine Graduate School of Medical Science, Kyoto 602-8566, Japan; ${ }^{5}$ Department of Preventive Medicine and Community Health, School of Medicine, University of Occupational and Environmental Health, Kitakyusyu 807-8555, Japan; 'Department of Public Health, Fujita Health University School of Health Sciences, Toyoake 470-1192, Japan; ${ }^{7}$ Department of Epidemiology for Community Health and Medicine, Kyoto Prefectural University of Medicine Graduate School of Medical Science, Kyoto 602-8566, Japan; ${ }^{8}$ Department of Public Health, Sapporo Medical University School of Medicine, Sapporo 060-8556, Japan and ${ }^{9}$ Department of Public Health, Hokkaido University Graduate School of Medicine, Sapporo 060-8638, Japan

Background: We examined the associations of intakes of vegetables and carotenes with risk of prostate cancer in Japanese.

Methods: A total of 15471 Japanese men participating in the Japan Collaborative Cohort study completed a questionnaire including food intake. Of them, 143 incident prostate cancers were documented. We examined the associations stated above by using Cox proportional hazard model.

Results: Vegetable intake was not associated with the risk of prostate cancer, but so was dietary alpha-carotene intake. The multivariable hazard ratio $(95 \% \mathrm{Cl})$ in the secondary highest and highest quintiles of alpha-carotene intake was $0.50(0.26-0.98)$ $(P=0.043)$ and $0.46(0.22-0.97)(P=0.041)(P$ for trend $=0.224)$, respectively. Beta-carotene intake was not associated with the risk of prostate cancer.

Conclusion: Alpha-carotene intake was associated with lower risk of prostate cancer among Japanese.

Prostate cancer is one of the most common cancers among men. Several epidemiological studies have identified age, family history (Kiciński et al, 2011) and obesity (MacInnis and English, 2006) as risk factors for prostate cancer. The intakes of tomato and lycopene, a type of carotene, was reported to associate inversely with the risk of prostate cancer (Chen et al, 2001; Giovannucci et al, 2002); however, the reported associations between the intake of other vegetables or other carotenes and the risk of prostate cancer have been inconsistent (Kirsh et al, 2007; Takachi et al, 2010).

The aim of the present study was to determine the association between the intake of vegetables and carotene and the risk of prostate cancer in Japanese whose consumption of vegetables seems higher than those in Westerners (Blanck et al, 2008; Ministry of Health, Labour and Welfare, 2011). Our a priori hypothesis is that the intake of vegetables or carotenes is inversely associated with the risk of prostate cancer. 


\section{MATERIALS AND METHODS}

The Japan Collaborative Cohort (JACC) Study for Evaluation of Cancer Risks, sponsored by the Ministry of Education, Sport, and Science, was conducted from 1988 to 1990 . The sampling methods and protocols of the JACC Study have been described elsewhere (Tamakoshi et al, 2013). A total of 46395 men, 40-79 years of age, completed self-administered questionnaires about their lifestyles and medical histories. Of them, we used the data of 26429 men who lived in 24 communities that underwent follow-up research of cancer incidence. We additionally excluded 10023 men owing to the lack of valid responses to dietary intake-related questions, and
935 men owing to the presence of past history of cancer and cardiovascular disease at baseline. Finally, we used the data of 15471 men for analysis.

The incidence of prostate cancer was based on the records of population-based cancer registries. The incidence data were coded by the 10th revision of the International Statistical Classification of Diseases and Related Health Problems. We used the first diagnosis for incidence. We defined prostate cancer as C61. The incidence of prostate cancer in the present study was similar to that estimated from the Japan cancer registry (Matsuda et al, 2013).

Each participant recorded the frequency of the intake of 35 foods which included five items for vegetable intake as cabbage/ head lettuce, Chinese cabbage, tomato, carrot/pumpkin and

Table 1. Characteristics of the subjects according to quintiles of frequency of vegetable intake and quintiles of amount of carotene intake

\begin{tabular}{|c|c|c|c|c|c|c|}
\hline & \multicolumn{5}{|c|}{ Quintiles } & \multirow[b]{2}{*}{$P$ for ANOVA } \\
\hline & 1 (low) & 2 & 3 & 4 & 5 (high) & \\
\hline \multicolumn{7}{|l|}{ Total vegetable intake } \\
\hline $\begin{array}{l}\text { Frequency of total vegetable intake (serves per week) } \\
N \\
\text { Age (years) } \\
\text { Body mass index }\left(\mathrm{kg} \mathrm{m}^{-2}\right)^{\mathrm{a}} \\
\text { Current drinker }(\%)^{\mathrm{a}} \\
\text { Current smoker }(\%)^{\mathrm{a}} \\
\text { Family history of prostate cancer (\%) }\end{array}$ & $\begin{array}{l}1.0-8.0 \\
3113 \\
54.4 \\
22.7 \\
75 \\
58 \\
0.3\end{array}$ & $\begin{array}{l}8.3-11.9 \\
3086 \\
55.0 \\
22.6 \\
77 \\
53 \\
0.3\end{array}$ & $\begin{array}{l}12.0-15.5 \\
3103 \\
55.9 \\
22.7 \\
77 \\
52 \\
0.4\end{array}$ & $\begin{array}{l}15.8-20.5 \\
3113 \\
56.5 \\
22.6 \\
76 \\
52 \\
0.2\end{array}$ & $\begin{array}{l}20.9-33.0 \\
3056 \\
57.7 \\
22.7 \\
74 \\
50 \\
0.5\end{array}$ & $\begin{array}{c}<0.001 \\
0.457 \\
0.025 \\
<0.001 \\
0.272\end{array}$ \\
\hline \multicolumn{7}{|l|}{ Green and yellow vegetable intake } \\
\hline $\begin{array}{l}\text { Frequency of green and yellow vegetable intake (serves per week) } \\
N \\
\text { Age (years) } \\
\text { Body mass index }\left(\mathrm{kg} \mathrm{m}^{-2}\right)^{\mathrm{a}} \\
\text { Current drinker }(\%)^{\mathrm{a}} \\
\text { Current smoker (\%) } \\
\text { Family history of prostate cancer (\%) }\end{array}$ & $\begin{array}{c}1.0-4.9 \\
2989 \\
54.0 \\
22.6 \\
75 \\
60 \\
0.3\end{array}$ & $\begin{array}{c}5.0-6.9 \\
2928 \\
54.9 \\
22.7 \\
77 \\
54 \\
0.3\end{array}$ & $\begin{array}{c}7.0-9.5 \\
3268 \\
55.7 \\
22.7 \\
77 \\
50 \\
0.3\end{array}$ & $\begin{array}{c}10.0-12.5 \\
3423 \\
56.9 \\
22.7 \\
77 \\
53 \\
0.4\end{array}$ & $\begin{array}{l}13.5-19.0 \\
2863 \\
57.9 \\
22.6 \\
73 \\
48 \\
0.5\end{array}$ & $\begin{array}{c}<0.001 \\
0.211 \\
<0.001 \\
<0.001 \\
0.623\end{array}$ \\
\hline \multicolumn{7}{|l|}{ Other vegetable intake } \\
\hline $\begin{array}{l}\text { Frequency of other vegetable intake (serves per week) } \\
N \\
\text { Age (years) } \\
\text { Body mass index }\left(\mathrm{kg} \mathrm{m}^{-2}\right)^{\mathrm{a}} \\
\text { Current drinker }(\%)^{\mathrm{a}} \\
\text { Current smoker (\%) } \\
\text { Family history of prostate cancer (\%) }\end{array}$ & $\begin{array}{c}0-1.9 \\
2762 \\
55.7 \\
22.6 \\
75 \\
56 \\
0.2\end{array}$ & $\begin{array}{c}3.0-3.5 \\
3367 \\
55.4 \\
22.7 \\
76 \\
53 \\
0.3\end{array}$ & $\begin{array}{c}3.9-5.0 \\
2798 \\
55.8 \\
22.7 \\
76 \\
52 \\
0.3\end{array}$ & $\begin{array}{c}7.0-8.5 \\
3892 \\
56.0 \\
22.7 \\
75 \\
52 \\
0.4\end{array}$ & $\begin{array}{c}10.5-14.0 \\
2652 \\
56.8 \\
22.8 \\
76 \\
53 \\
0.5\end{array}$ & $\begin{array}{c}<0.001 \\
0.077 \\
0.530 \\
0.022 \\
0.368\end{array}$ \\
\hline \multicolumn{7}{|l|}{ Alpha-carotene intake } \\
\hline $\begin{array}{l}\text { Median alpha-carotene intake }\left(\mu \mathrm{g} \mathrm{day}^{-1}\right) \\
N \\
\text { Age (years) } \\
\text { Body mass index }\left(\mathrm{kg} \mathrm{m}^{-2}\right)^{\mathrm{a}} \\
\text { Current drinker }(\%)^{\mathrm{a}} \\
\text { Current smoker }(\%)^{\mathrm{a}} \\
\text { Family history of prostate cancer (\%) }\end{array}$ & $\begin{array}{c}105 \\
3094 \\
53.7 \\
22.6 \\
82 \\
60 \\
0.2\end{array}$ & $\begin{array}{c}175 \\
3094 \\
54.8 \\
22.6 \\
77 \\
55 \\
0.3\end{array}$ & $\begin{array}{c}236 \\
3095 \\
55.9 \\
22.7 \\
75 \\
52 \\
0.3\end{array}$ & $\begin{array}{c}317 \\
3094 \\
56.9 \\
22.7 \\
74 \\
50 \\
0.4\end{array}$ & $\begin{array}{c}497 \\
3094 \\
58.2 \\
22.7 \\
70 \\
49 \\
0.5\end{array}$ & $\begin{array}{c}<0.001 \\
0.189 \\
<0.001 \\
<0.001 \\
0.347\end{array}$ \\
\hline \multicolumn{7}{|l|}{ Beta-carotene intake } \\
\hline $\begin{array}{l}\text { Median beta-carotene intake }\left(\mu \mathrm{g} \mathrm{day}^{-1}\right) \\
N \\
\text { Age (years) } \\
\text { Body mass index }\left(\mathrm{kg} \mathrm{m}^{-2}\right)^{\mathrm{a}} \\
\text { Current drinker }(\%)^{\mathrm{a}} \\
\text { Current smoker }(\%)^{\mathrm{a}} \\
\text { Family history of prostate cancer (\%) }\end{array}$ & $\begin{array}{c}986 \\
3094 \\
53.1 \\
22.6 \\
81 \\
60 \\
0.2\end{array}$ & $\begin{array}{c}1569 \\
3094 \\
54.4 \\
22.7 \\
76 \\
54 \\
0.4\end{array}$ & $\begin{array}{c}2107 \\
3095 \\
56.0 \\
22.7 \\
77 \\
51 \\
0.3\end{array}$ & $\begin{array}{c}2739 \\
3094 \\
57.2 \\
22.7 \\
74 \\
51 \\
0.3\end{array}$ & $\begin{array}{c}3718 \\
3094 \\
58.8 \\
22.7 \\
70 \\
48 \\
0.5\end{array}$ & $\begin{array}{c}<0.001 \\
0.527 \\
<0.001 \\
<0.001 \\
0.304\end{array}$ \\
\hline
\end{tabular}


spinach/garland chrysanthemum. Five responses were possible for 33 food items including vegetables: 'rarely', '1-2 days per month', '1-2 days per week', '3-4 days per week' and 'almost every day'; the consumption of each food was calculated by multiplying the frequency score of consumption of each food 0, 0.38, 1.5, 3.5 and 7 , respectively. As for soybean paste soup and rice intake, the frequency and number of cups/bowls per day were recorded. We determined the non-valid data as follows: the missing for rice intake, miso soup intake, alcohol intake, $\geqslant 5$ items out of 33 food items; and/or extremely low or high total energy intakes $(<800$ kcal day ${ }^{-1}$ or $\left.>4000 \mathrm{kcal}_{\text {day }}{ }^{-1}\right)$. The reproducibility and validity of this dietary questionnaire were reported elsewhere (Date et al, 2005). The energy-adjusted nutrient intake was calculated by the residual method. The frequency of total vegetable intake was calculated by totalling the frequency of cabbage/head lettuce, Chinese cabbage, tomato, carrot/pumpkin and spinach/ garland chrysanthemum intakes. The frequency of green and yellow vegetable intakes was calculated by totalling the frequency of tomato, carrot/pumpkin and spinach/garland chrysanthemum intakes. The frequency of other vegetable was calculated by totalling the frequency of cabbage/head lettuce and Chinese cabbage.

Statistical analysis was based on incident rates of prostate cancer during the follow-up period from 1989 to 2009. For each participant, the person-years of follow-up were calculated from the date of filling out the baseline questionnaire to death, moving out of the community, or the end of follow up, whichever was first. The median follow-up period was 16.0 years. The number of moving out was 821 .

Age-adjusted and multivariable-adjusted hazard ratios of prostate cancer were defined as the incidence rate among participants according to quintiles of frequency of vegetable intake and quintiles of amount of carotene intake. The hazard ratios of prostate cancer and their 95\% confidence intervals (95\% CI) were calculated after adjustment for age and potential confounding factors by using the Cox proportional hazard model. These confounding variables included body mass index $\left(\mathrm{kg} \mathrm{m}^{-2}\right)$, smoking status (never, ex-smoker and current smoke), ethanol intake (current drinker or not), daily green tea intake (yes or no) and work schedule (rotating-shift or not). We also used the quintiles of frequency of dairy products, bean products, fish products and beef intake as confounding variables with analyses of vegetable intake. We used quintiles of saturated fatty acid, isoflavone and alpha-tocopherol intake as confounding variables with analyses of carotene intake. Test for a linear trend across the vegetable and carotene intake quintiles were conducted by linear regression using the median variable of vegetable and carotene intake in each quintile. We tested the interaction of alcohol intake and smoking for each analysis, and found no significant interactions. As for family history of prostate cancer, we found no cases with it. Thus, we did not include it as a confounding variable.

Table 2. Associations between quintiles of frequency of vegetable intake and risk of prostate cancer

Quintiles of frequency of vegetable intake

\begin{tabular}{|l|l|l|l|l|l|}
\hline 1 (low) & 2 & 3 & 4 & 5 (high) & P for trend
\end{tabular}

Total vegetable intake

Total vegetable intake (serves per week)

Number of subjects

Person-years

Number of events

Number of events (per 1000 person-years)

Age-adjusted

Multivariable-adjusted ${ }^{a}$

Multivariable-adjusted ${ }^{\mathbf{b}}$

Green and yellow vegetable intake

Green and yellow vegetable intake (serves per week)

Number of subjects

Person-years

Number of events

Number of events (per 1000 person-years)

Age-adjusted

Multivariable-adjusted ${ }^{\mathrm{a}}$

Multivariable-adjusted ${ }^{\text {b }}$

\begin{tabular}{c|c|c|}
\hline $1.0-8.0$ & $8.3-11.9$ & $12.0-15.5$ \\
3113 & 3086 & 3103 \\
40293 & 40827 & 41118 \\
28 & 22 & 31 \\
0.69 & 0.54 & 0.75 \\
1.00 & $0.74(0.42-1.29)$ & $0.95(0.57-1.58)$ \\
1.00 & $0.72(0.41-1.26)$ & $0.93(0.56-1.56)$ \\
1.00 & $0.63(0.36-1.10)$ & $0.77(0.45-1.30)$
\end{tabular}

15.8-20.5

3113

41506

26

0.63

$0.74(0.44-1.27)$

$0.72(0.42-1.24)$

$0.55(0.31-0.96)$

$20.9-33.0$
3056
40870

36

0.88

$0.94(0.57-1.55)$

$0.90(0.54-1.48)$

$0.65(0.37-1.12)$
0.602

0.767 0.294

\section{Other vegetable intake}

Other vegetable intake (serves per week)

Number of subjects

Person-years

Number of events

Number of events (per 1000 person-years)

Age-adjusted

Multivariable-adjusted ${ }^{a}$

Multivariable-adjusted ${ }^{\text {b }}$

\begin{tabular}{|c|c|}
\hline $1.0-4.9$ & $5.0-6.9$ \\
2989 & 2928 \\
39213 & 38865 \\
24 & 23 \\
0.61 & 0.59 \\
1.00 & $0.88(0.50-1.56)$ \\
1.00 & $0.86(0.48-1.53)$ \\
1.00 & $0.76(0.43-1.37)$
\end{tabular}

$7.0-9.5$
3268
43386
29
0.67
$(0.55-1.64)$
$(0.54-1.59)$
$(0.43-1.32)$

\begin{tabular}{c|}
$10.0-12.5$ \\
3423 \\
45730 \\
37 \\
0.81 \\
$01(0.60-1.69)$ \\
$98(0.59-1.65)$ \\
$76(0.44-1.32)$
\end{tabular}

$13.5-19.0$
2863
37420
30
0.80
$92(0.54-1.58)$
$87(0.50-1.50)$
$61(0.34-1.10)$

0.740

0.913

0.200

${ }^{\text {a }}$ Adjusted for age, body mass index ( $\mathrm{kg} \mathrm{m}^{-2}$ ), ethanol intake (current drinker or not), smoking status (three categories), daily green tea intake (yes or no) and work schedule (rotating-shift or not). ${ }^{\mathbf{b}}$ Adjusted further for frequency of dairy products intake (quintiles), soy products intake (quintiles), fish products intake (quintiles) and beef intake (five categories). 
The present study was approved by the ethics committees of Nagoya University School of Medicine and Kyoto Prefectural University of Medicine Graduate School of Medical Science.

We used SAS version 9.3 software (SAS Institute Inc., Cary, NC, USA) in all analyses.

\section{RESULTS}

The characteristics of subjects according to vegetable intake and carotene intake are summarised in Table 1. Intakes of total, green and yellow and other vegetables, and alpha- and beta-carotenes were correlated positively with age, but negatively with the proportion of current smokers. Intakes of total, green and yellow vegetables, and alpha- and beta-carotenes were correlated inversely with the proportion of current drinkers.

During the follow-up, 143 incident cases of prostate cancer were documented. Table 2 presents the age-adjusted and multivariateadjusted hazard ratios (95\% CI) according to the quintiles of frequency of vegetable intake. With regard to total vegetable intake, compared with the lowest quintile, other quintiles showed lower risk of prostate cancer. The relationship between total vegetable intake and risk of prostate cancer showed a threshold pattern with lower risk in the secondary lowest and higher quintiles of total vegetable intake. The multivariate hazard ratio $(95 \% \mathrm{CI})$ in the secondary highest versus the lowest quintiles was $0.55(0.31-0.96)$ $(P=0.035)$ and in the highest versus lowest quintiles was 0.65 $(0.37-1.12)(P=0.116)(P$ for trend $=0.294)$. Green and yellow vegetable intake and other vegetable intake were not associated with the risk of prostate cancer.

Table 3 shows the hazard ratios (95\% CI) according to quintiles of carotene intake. As for alpha-carotene intake, compared with the lowest quintile, the highest and the secondary lowest quintile showed lower risk of prostate cancer. The relationship between alpha-carotene intake and risk of prostate cancer showed a threshold pattern with lower risk in the secondary lowest and higher quintiles of alpha-carotene intake. The multivariate hazard ratio $(95 \% \mathrm{CI})$ in the secondary highest and highest versus lowest quintile of alpha-carotene intake was $0.50(0.26-0.98)(P=0.043)$ and $0.46(0.22-0.97) \quad(P=0.041) \quad(P$ for trend $=0.224)$. Betacarotene intake was not associated with risk of prostate cancer.

\section{DISCUSSION}

The main finding of this large prospective study of Japanese men was that vegetable intake was not associated with the risk of prostate cancer; however, a possible threshold effect was suggested. Moderate to high alpha-carotene intake was associated with lower risk of prostate cancer.

A previous prospective study of Japanese showed no significant association between total vegetable intake and risk of prostate cancer (Takachi et al, 2010). Other prospective studies also reported no association between vegetable intake and risk of prostate cancer (Hsing et al, 1990; Schuurman et al, 1998). However, two prospective studies of US men indicated inverse association between vegetable or vegetable fat intake and risk of prostate cancer progression (Kirsh et al, 2007; Richman et al, 2013). As for the association between alpha-carotene intake and risk of prostate cancer, no other prospective study has examined it.

Several mechanisms may account for the inverse association of vegetable and carotene intake and risk of prostate cancer. First, prostate cancer cells carry numerous genome defects which allow malignant cell growth and survival (Nelson et al, 2009). Vegetable components such as glucosinolates and isothiocyanates stimulate cancer cell apoptosis and activate phase 2 enzyme that detoxificates carcinogen (Hayes et al, 2008, Ho et al, 2009). For example, sulforaphane, one of isothiocyanates, acts as a histone deacetylase inhibitor which allows DNA to open their chromatin and proceed RNA transcription (Richon et al, 2000). That effect activates tumour suppressor genes such as P21 which induces cell cycle arrest of damaged DNA and Bax which induces apoptosis through the stimulation of anion channel (Ho et al, 2009). Second, carotene intake reduces cancer cell generation through the inhibition of

\begin{tabular}{|c|c|c|c|c|c|c|}
\hline & \multicolumn{5}{|c|}{ Quintiles of each nutrition intake } & \multirow[b]{2}{*}{$P$ for trend } \\
\hline & 1 (low) & 2 & 3 & 4 & 5 (high) & \\
\hline \multicolumn{7}{|l|}{ Alpha-carotene } \\
\hline $\begin{array}{l}\text { Median alpha-carotene intake }\left(\mu \mathrm{g} \mathrm{day}^{-1}\right) \\
\text { Number of subjects } \\
\text { Person-years } \\
\text { Number of events } \\
\text { Number of events (per } 1000 \text { person-years) } \\
\text { Age-adjusted } \\
\text { Multivariable-adjusted }^{\mathbf{a}} \\
\text { Multivariable-adjusted }^{\mathbf{b}}\end{array}$ & $\begin{array}{c}105 \\
3094 \\
37902 \\
22 \\
0.58 \\
1.00 \\
1.00 \\
1.00\end{array}$ & \begin{tabular}{|c|}
175 \\
3094 \\
40786 \\
18 \\
0.44 \\
$0.61(0.33-1.15)$ \\
$0.60(0.32-1.13)$ \\
$0.50(0.26-0.98)$
\end{tabular} & $\begin{array}{c}236 \\
3095 \\
41688 \\
25 \\
0.60 \\
0.74(0.42-1.32) \\
0.71(0.40-1.27) \\
0.55(0.28-1.08)\end{array}$ & $\begin{array}{c}317 \\
3094 \\
42456 \\
45 \\
1.06 \\
1.16(0.69-1.95) \\
1.10(0.65-1.86) \\
0.77(0.39-1.51)\end{array}$ & \begin{tabular}{|c|}
496 \\
3094 \\
41783 \\
33 \\
0.79 \\
$0.81(0.47-1.40)$ \\
$0.74(0.42-1.29)$ \\
$0.46(0.22-0.97)$
\end{tabular} & $\begin{array}{l}0.173 \\
0.333 \\
0.224\end{array}$ \\
\hline \multicolumn{7}{|l|}{ Beta-carotene } \\
\hline $\begin{array}{l}\text { Median beta-carotene intake }\left(\mu \mathrm{g} \mathrm{day}^{-1}\right) \\
\text { Number of subjects } \\
\text { Person-years } \\
\text { Number of events } \\
\text { Number of events (per } 1000 \text { person-years) } \\
\text { Age-adjusted } \\
\text { Multivariable-adjusted }^{\mathbf{a}} \\
\text { Multivariable-adjusted }^{\mathbf{b}}\end{array}$ & $\begin{array}{c}986 \\
3094 \\
39331 \\
22 \\
0.56 \\
1.00 \\
1.00 \\
1.00\end{array}$ & \begin{tabular}{|c|}
1569 \\
3094 \\
41197 \\
22 \\
0.53 \\
$0.77(0.42-1.39)$ \\
$0.74(0.41-1.34)$ \\
$0.65(0.33-1.26)$
\end{tabular} & $\begin{array}{c}2107 \\
3095 \\
41397 \\
29 \\
0.70 \\
0.90(0.51-1.57) \\
0.85(0.49-1.50) \\
0.67(0.33-1.37)\end{array}$ & \begin{tabular}{|c|}
2739 \\
3094 \\
41638 \\
30 \\
72.00 \\
$0.83(0.48-1.45)$ \\
$0.79(0.45-1.39)$ \\
$0.52(0.24-1.14)$
\end{tabular} & \begin{tabular}{|c|}
3718 \\
3094 \\
41052 \\
40 \\
0.97 \\
$0.97(0.57-1.65)$ \\
$0.90(0.52-1.54)$ \\
$0.51(0.22-1.19)$
\end{tabular} & $\begin{array}{l}0.218 \\
0.351 \\
0.200\end{array}$ \\
\hline
\end{tabular}


systemic inflammation which is a known risk factor of prostate cancer (Sfanos and De Marzo, 2012). A randomized controlled trial showed that a high intake of carotenoid-rich vegetables and fruits lowered plasma C-reactive protein concentrations, a biomarker of systemic inflammation (Watzl et al. 2005). Third, alpha-carotene has a stronger inhibitory effect on carcinogenesis than betacarotene according to an animal study (Murakoshi et al, 1992). It accorded with our finding that alpha-carotene intake, but not beta-carotene, was inversely associated with the risk of prostate cancer.

The strengths of the present study include the study design and subjects. We used a large prospective cohort enrolled from the Japanese general populations, and we first showed inverse association between alpha-carotene intake and risk of prostate cancer in Asian populations.

As for a limitation of the present study, we did not obtain the information about TNM stage, Gleason score and pathological stage. Therefore, we could not evaluate the effect of vegetable and carotene intake on the advancement of prostate cancer. However, a previous cohort study of Japanese showed that vegetable intake was not associated with risk of localised or advanced prostate cancer (Takachi et al, 2010).

In conclusion, our large prospective study of Japanese men indicated that moderate to high alpha-carotene intakes may contribute to reduced risk of prostate cancer.

\section{ACKNOWLEDGEMENTS}

The authors express their appreciation to Dr Kunio Aoki, Professor Emeritus, Nagoya University School of Medicine and the former Chairman of the JACC Study, and to Dr Haruo Sugano, the former Director of the Cancer Institute, Tokyo, who greatly contributed to the initiation of the JACC Study.

\section{CONFLICT OF INTEREST}

The authors declare no conflict of interest.

\section{REFERENCES}

Blanck HM, Gillespie C, Kimmons JE, Seymour JD, Serdula MK (2008) Trends in fruit and vegetable consumption among U.S. men and women, 1994-2005. Prev Chronic Dis 5: A35.

Chen L, Stacewicz-Sapuntzakis M, Duncan C, Sharifi R, Ghosh L, van Breemen R, Ashton D, Bowen PE (2001) Oxidative DNA damage in prostate cancer patients consuming tomato sauce-based entrees as a whole-food intervention. J Natl Cancer Inst 93: 1872-1879.

Date C, Fukui M, Yamamoto A, Wakai K, Ozeki A, Motohashi Y, Adachi C, Okamoto N, Kurosawa M, Tokudome Y, Kurisu Y, Watanabe Y, Ozasa K, Nakagawa S, Tokui N, Yoshimura T, Tamakoshi A. for the JACC Study Group (2005) Reproducibility and validity of a self-administered food frequency questionnaire used in JACC Study. J Epidemiol 15: S9-23.
Giovannucci E, Rimm EB, Liu Y, Stampfer MJ, Willett WC (2002) A prospective study of tomato products, lycopene, and prostate cancer risk. J Natl Cancer Inst 94: 391-398.

Hayes JD, Kelleher MO, Eggleston IM (2008) The cancer chemopreventive actions of phytochemicals derived from glucosinolates. Eur J Nutr 47: S73-S88.

Ho E, Clarke JD, Dashwood RH (2009) Dietary sulforaphane, a histone deacetylase inhibitor for cancer prevention. J Nutr 139: 2393-2396.

Hsing AW, McLaughlin JK, Schuman LM, Bjelke E, Gridley G, Wacholder S, Chien HT, Blot WJ (1990) Diet, tobacco use, and fatal prostate cancer: results from the Lutheran Brotherhood Cohort Study. Cancer Res 50: 6836-6840.

Kiciński M, Vangronsveld J, Nawrot TS (2011) An epidemiological reappraisal of the familial aggregation of prostate cancer: a meta-analysis. PLoS One 6: e27130.

Kirsh VA, Peters U, Mayne ST, Subar AF, Chatterjee N, Johnson CC, Hayes RB; Prostate, lung, colorectal and ovarian cancer screening trial (2007) Prospective study of fruit and vegetable intake and risk of prostate cancer. J Natl Cancer Inst 99: 1200-1209.

Matsuda A, Matsuda T, Shibata A, Katanoda K, Sobue T, Nishimoto H. The Japan Cancer Surveillance Research Group (2013) Cancer incidence and incidence rates in Japan in 2007: a study of 21 population-based cancer registries for the Monitoring of Cancer Incidence in Japan (MCIJ) Project. Jpn J Clin Oncol 43: 328-336.

MacInnis RJ, English DR (2006) Body size and composition and prostate cancer risk: systematic review and meta-regression analysis. Cancer Causes Control 17: 989-1003.

Ministry of Health, Labour and Welfare (2011) The National Nutrition Survey in Japan, 2008. Daiichi Shuppan: Tokyo, in Japanese.

Murakoshi M, Nishino H, Satomi Y, Takayasu J, Hasegawa T, Tokuda H, Iwashima A, Okuzumi J, Okabe H, Kitano H, Iwasaki R (1992) Potent preventive action of alpha-carotene against carcinogenesis: spontaneous liver carcinogenesis and promoting stage of lung and skin carcinogenesis in mice are suppressed more effectively by alpha-carotene than by betacarotene. Cancer Res 52: 6583-6587.

Nelson WG, De Marzo AM, Yegnasubramanian S (2009) Epigenetic alterations in human prostate cancers. Endocrinology 150: 3991-4002.

Richman EL, Kenfield SA, Chavarro JE, Stampfer MJ, Giovannucci EL, Willett WC, Chan JM (2013) Fat intake after diagnosis and risk of lethal prostate cancer and all-cause mortality. JAMA Intern Med 173: 1318-1326.

Richon VM, Sandhoff TW, Rifkind RA, Marks PA (2000) Histone deacetylase inhibitor selectively induces p21WAF1 expression and gene-associated histone acetylation. Proc Natl Acad Sci USA. 97: 10014-10019.

Schuurman AG, Goldbohm RA, Dorant E, van den Brandt PA (1998) Vegetable and fruit consumption and prostate cancer risk: a cohort study in The Netherlands. Cancer Epidemiol Biomarkers Prev 7: 673-680.

Sfanos KS, De Marzo AM (2012) Prostate cancer and inflammation: the evidence. Histopathology 60: 199-215.

Takachi R, Inoue M, Sawada N, Iwasaki M, Sasazuki S, Ishihara J, Tsubono Y, Tsugane S. Japan Public Health Center-Based Prospective Study Group (2010) Fruits and vegetables in relation to prostate cancer in Japanese men: the Japan Public Health Center-Based Prospective Study. Nutr Cancer 62: 30-39.

Tamakoshi A, Ozasa K, Fujino Y, Suzuki K, Sakata K, Mori M, Kikuchi S, Iso H. for the JACC Study Group (2013) Cohort profile of the Japan Collaborative Cohort Study at final follow-up. J Epidemiol 23: 227-232.

Watzl B, Kulling SE, Möseneder J, Barth SW, Bub A (2005) A 4-wk intervention with high intake of carotenoid-rich vegetables and fruit reduces plasma C-reactive protein in healthy, nonsmoking men. Am J Clin Nutr 82: 1052-1058. 